\title{
DICENTRIC CHROMOSOME 14;18 PLUS TWO ADDITIONAL CNVS IN A GIRL WITH MICROFORM HOLOPROSENCEPHALY AND TURNER STIGMATA
}

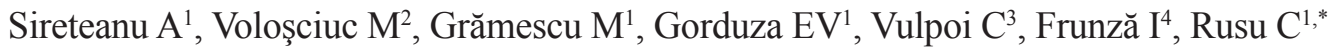

*Corresponding Author: Cristina Rusu, M.D., Ph.D., "Grigore T. Popa" University of Medicine and Pharmacy, Medical Genetics Department, Stradă Universităţii 16, Iaşi 700115, Romania; Tel./Fax: +40-232-272-754; Mobile: +40-745-432-077; E-mail address: abcrusu@gmail.com

\section{ABSTRACT}

We report a 20 -year-old female with features evocative of Turner syndrome (short stature, broad trunk, mild webbed neck), dysmorphic face, minor features of holo-prosencephaly (HPE), small hands and feet, excessive hair growth on anterior trunk and intellectual disability. Cytogenetic analysis identified a pseudodicentric 14;18 chromosome. Genome wide single nucleotide polymorphism (SNP) array showed a terminal deletion of approximately $10.24 \mathrm{Mb}$, from 18 p11.32 to 18 p11.22, flanked by a duplication of approximately $1.15 \mathrm{Mb}$, from $18 \mathrm{p} 11.22$ to $18 \mathrm{p} 11.21$. In addition, the SNP array revealed a duplication of $516 \mathrm{~kb}$ in 16p11.2. We correlated the patient's clinical findings with the features mentioned in the literature for these copy number variations. This case study shows the importance of microarray analysis in the detection of cryptic chromosomal rearrangements in patients with intellectual disability and multiple congenital anomalies.

Keywords: $18 \mathrm{p}$ - syndrome; Holoprosencephaly (HPE); Single nucleotide polymorphism (SNP) array; 16p11.2 duplication

\footnotetext{
$\overline{{ }^{1} \text { Department of Medical Genetics, "Grigore T. Popa" University of }}$ Medicine and Pharmacy, Iaşi, Romania

${ }^{2}$ Medical Genetics Center, "Sf. Maria” Children's Hospital, Iaşi, Romania

${ }^{3}$ Department of Endocrinology, "Grigore T. Popa" University of Medicine and Pharmacy, Iaşi, Romania

${ }^{4}$ Department of Neurology, CF Hospital, Iaşi, Romania
}

\section{INTRODUCTION}

Monosomy 18p was first reported in 1963 by de Grouchy et al. [1] and has an incidence of 1:50,000 live-born infants [2]. About two-thirds of cases are de novo deletions, one-sixth are due to de novo translocations between the long arms of an acrocentric and $18 \mathrm{q}$, and the rest come from familial translocations, inversions, complex translocations or direct transmission [3]. The main clinical features of monosomy $18 \mathrm{p}$ are mild to moderate intellectual disability (ID), postnatal growth retardation, and dysmorphic features including ptosis, hypertelorism, strabismus, broad flat nose, micrognathia, and low-set large ears [4]. We report on a girl with ID, mild dysmorphic face and masculine body habitus who had a de novo $14 ; 18$ translocation. Copy number analysis with single nucleotide polymorphism (SNP) array detected a terminal deletion flanked by a duplication on $18 \mathrm{p}$ and a duplication of 16p11.2.

\section{MATERIALS AND METHODS}

Case Report. The patient is a 20 -year-old female, the first child of non consanguineous, healthy Caucasian parents (mother was 24 years old and father was 27 years old when the proband was born). There was no family history of ID, congenital anomalies or psychiatric disorders. The pregnancy was uneventful; she was born at term by normal delivery with a birth weight of 2,200 $\mathrm{g}$ (below the 3rd percentile), length and head circumference were not recorded. All de- 


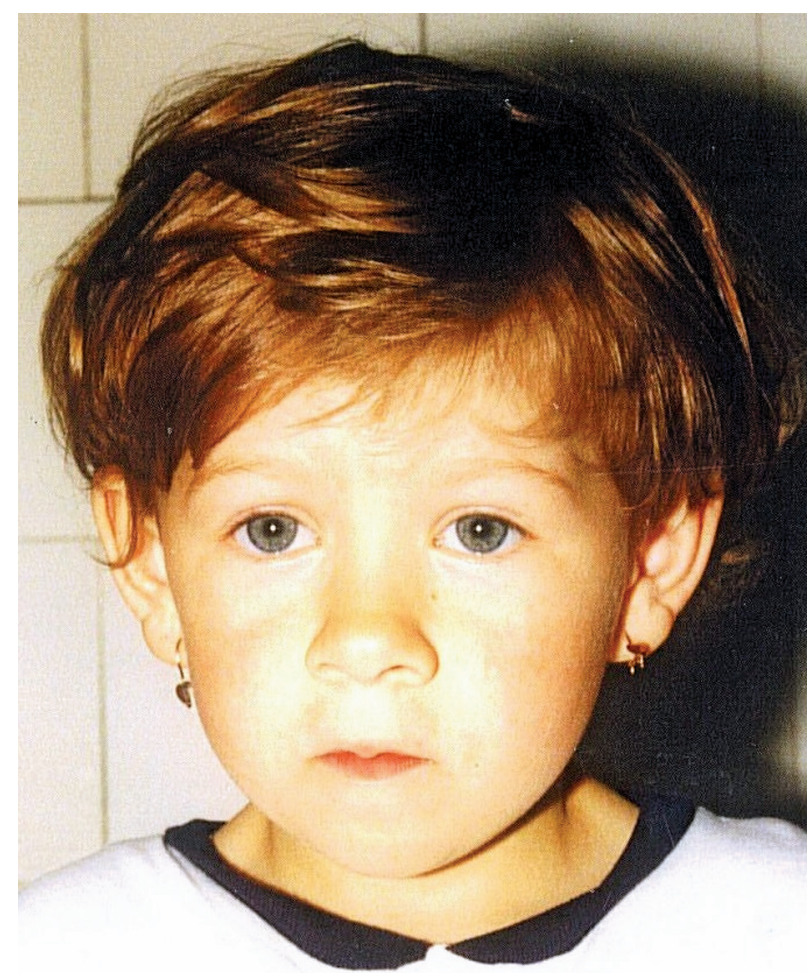

Figure 1. Patient at age 5.5 years.

velopmental milestones were delayed: she achieved head control at 6 months, walked without support at 2 years, spoke first clear words at 1.5 years. The girl was referred for genetic evaluation at the age of 5.5 year old, due to ID and single central maxillary incisor. Her growth parameters were: height $95.5 \mathrm{~cm}$ [-3.68 standard deviation (SD)], weight $13 \mathrm{~kg}(-2.48 \mathrm{SD})$, and head circumference $47 \mathrm{~cm}(-2.76 \mathrm{SD})$. She had a triangular face, horizontal palpebral fissures, blue sclera, short, slightly protruding philtrum and upper lip, blunted Cupid's bow, slightly everted lower lip, mild microretrognathia, bilateral preauricular sinus (Figure 1). Oral cavity examination showed absent maxillary and mandibular frenulum and single central maxillary incisor. Her language was limited to single words (she could not produce sentences). She had nocturnal and diurnal enuresis, for which she received therapy. No hearing impairment has been identified. Echocardiography showed an atrial septal defect. Abdominal ultrasound, routine biochemical and hematological tests, endocrine investigations [growth hormone (GH), free thyroxine (T4), thyroid-stimulating hormone (TSH)] were normal. No metabolic tests have been performed. Cranio-cerebral computed tomography (CT) scan and magnetic resonance imaging (MRI) of the spine did not show any changes.

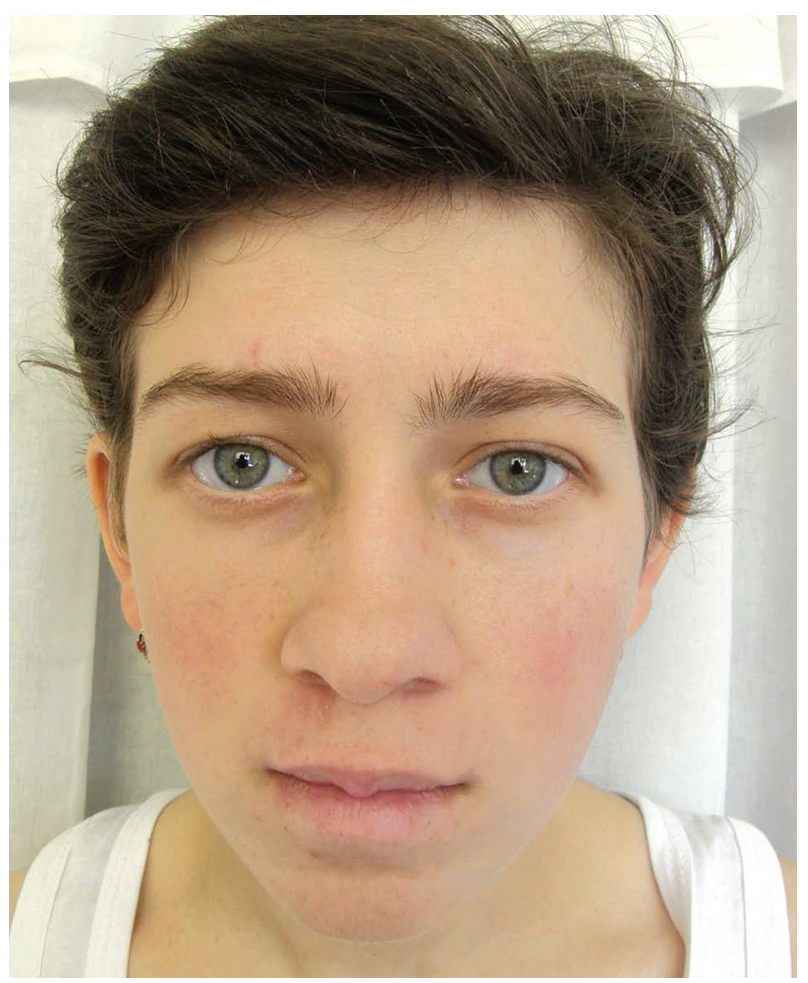

Figure 2. Patient at age 20 years.

When examined at the age of 20 , her height was $147 \mathrm{~cm}(-2.89 \mathrm{SD})$, weight was $43 \mathrm{~kg}$ [-1.76 SD, body mass index (BMI) $19.9 \mathrm{~kg} / \mathrm{m}^{2}$ ), and head circumference was $53 \mathrm{~cm}(-1.75 \mathrm{SD})$. We have noticed her standing and walking position (leaning slightly forward, with widened base of support), as well as slowness in motion and action. The face became elongated, mature for age, with slightly coarse features (Figure 2). She had mild webbed neck, broad chest and narrow hips, normal posterior hairline, kyphoscoliosis, pectus excavatum, short and wide hands and feet (below the 3rd percentile), with mild brachydactyly. Puberty was normal, but she developed asymmetric mammary glands and excessive hair growth in pre-sternal, circumareolar and subumibilical regions (Ferri-man-Gallwey score of 2). Psychological testing established a moderate ID (IQ 45), with impaired speech and language skills, difficulties with interpersonal relationships and oppositional behavior. She presented giggle incontinence. Endocrine investigations were as follows: normal levels of follicle-stimulating hormone (FSH), luteinizing hormone (LH), estradiol, prolactin, elevated plasmatic levels of testosterone, dehydroepiandrosterone (DHEA)-sulfate, and 17-hyroxyprogesterone $(\mathrm{OH})$. 


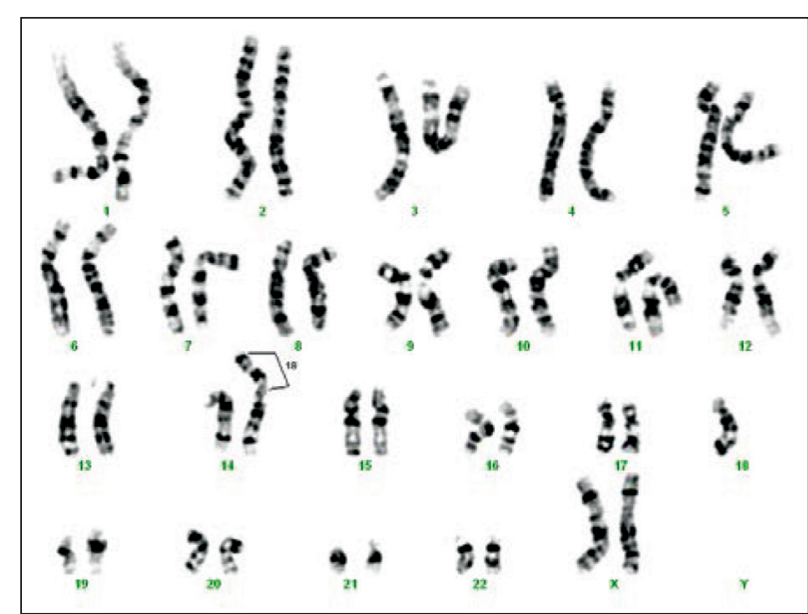

Figure 3. Karyotype of the proband demonstrating the $14 ; 18$ translocation.

\section{「(}

Figure 4. View of the C-banded derivative chromosome from two different metaphases showing the presence of two centromeres.

Cytogenetic Studies. The chromosome analysis was performed for the patient and her parents using the G-banding technique on metaphase chromosomes from peripheral blood lymphocytes, according to standard protocol. Chromosome C-banding was performed by the standard BSG (barium hydroxide/saline solution/Giemsa) method [5] with slight modifications.
Single Nucleotide Polymorphism Array. Genomic DNA was purified from peripheral blood using Wizard Genomic DNA Purification Kit (Promega Corp., Madison, WI, USA). The SNP array was performed using Human CytoSNP-12 v2.1 BeadChip platform (Illumina Inc., San Diego, CA), containing approximately 300,000 SNPs per sample, according to the manufacturer's instructions. The data were processed using Genome Studio V2010.1 software (Illumina). Genomic positions were defined according to the GRCh37/hg19 Assembly of the Human Genome (February 2009).

\section{RESULTS}

The cytogenetic G-banding revealed an unbalanced translocation between chromosomes 14 and 18 (Figure 3 ). The C-banding showed two centromeres on the derivative chromosome; in all metaphases examined the 14 chromosome centromere was inactivated (Figure 4). Thus, the karyotype was 45,XX,psu $\operatorname{dic}(14 ; 18)(\mathrm{p} 11.1 ; \mathrm{p} 13.1)$. The parental karyotypes were normal. The SNP array analysis detected a terminal deletion of approximately $10.24 \mathrm{Mb}$, from $18 \mathrm{p} 11.32$ to $18 \mathrm{p} 11.22(274-10,242,742)$, flanked by a duplication of approximately $1.15 \mathrm{Mb}$, from $18 \mathrm{p} 11.22$ to $18 p 11.21(10,249,343-11,401,062)$ (Figure 5). In addition, the SNP array revealed a duplication of 516,590 bp in 16 p11.2 $(29,568,718-30,085,308)$. The relatively small size of the duplications did not allow for fluorescent in situ hybridization (FISH) to determine the orientation. Blood samples from the parents were not available for SNP array analysis.

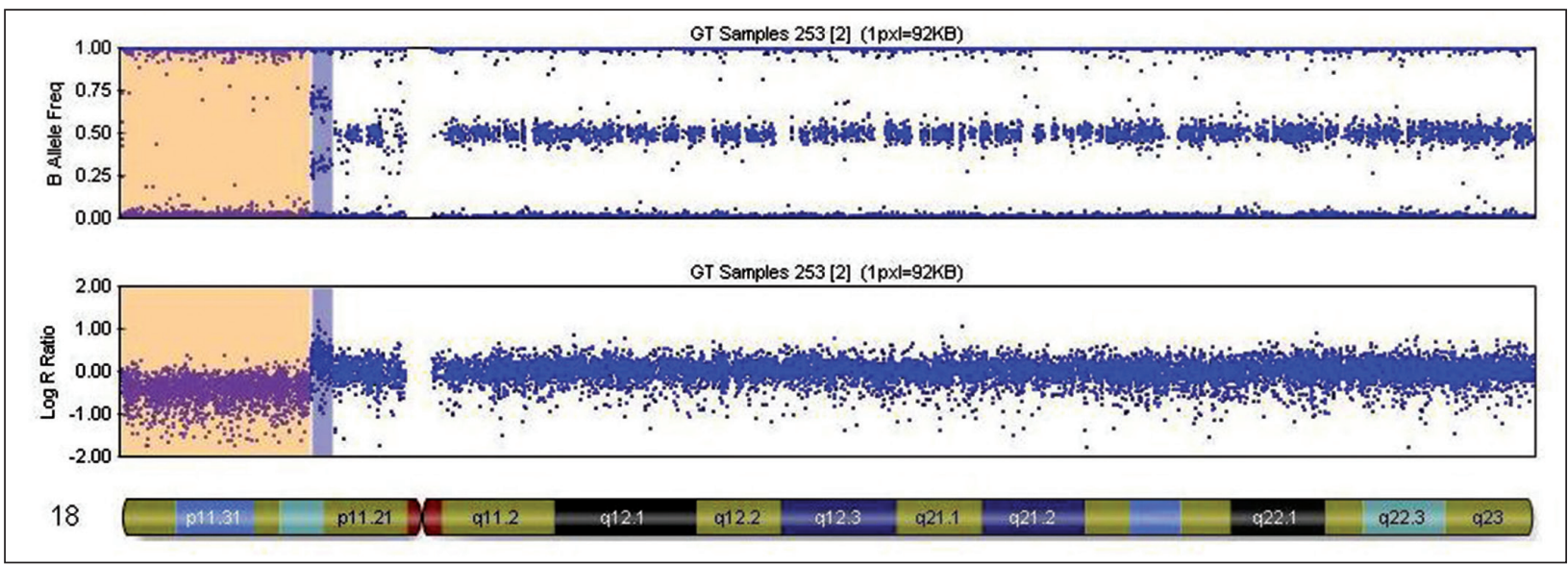

Figure 5. The SNP array results of chromosome 18 in the patient, showing a 10.24 Mb deletion in 18p11.32-p11.22 and a duplication of $1.15 \mathrm{Mb}$ in 18p11.22-p11.21. 


\section{DISCUSSION}

We describe a female patient with some signs of Turner syndrome, mild dysmorphic face, minor features of holoprosencephaly (HPE), small hands and feet, excessive hair growth on anterior trunk and ID. The karyotype showed an unbalanced translocation between chromosomes 14 and 18 resulting in the formation of a dicentric derivative chromosome. Single nucleotide polymorphism array analysis revealed three abnormalities: an 18p deletion flanked by a duplication, and a 16p11.2 duplication. The translocation is de novo as both parents had a normal karyotypes. Non Robertsonian dicentric autosomes are rare findings, reported in only 26 cases in a review by Lemyre et al. [6]. The majority of cases involve the acrocentric chromosomes, with a short arm breakpoint, followed in frequency by chromosome 18 . Most of the heterodicentric autosomes have only one primary constriction on metaphase chromosomes, and the constriction is noticed mostly at the site of the non-acrocentric centromere [6], as in our case.

Deletions of $\mathrm{p}$ arms of acrocentrics containing nucleolus organizer regions (NOR) regions are not known to be associated with phenotypic anomalies, and have therefore probably not contributed to the phenotype. Also, the $1.15 \mathrm{Mb} 18 \mathrm{p}$ duplication is not likely to have contributed to the phenotype, since most patients with trisomy $18 \mathrm{p}$ have normal or mild phenotypes, and may or may not have ID [7]. Our patient displays some of the features of $18 \mathrm{p}$ - syndrome, such as ID, features of the HPE spectrum (mild microcephaly, single central maxillary incisor), and features evocative of Turner syndrome (short stature, mild webbed neck, pectus excavatum, broad trunk and narrow hips) (Table 1). Facial dysmorphism (triangular face, blue sclera, bilateral preauricular sinus) is different from that described for $18 \mathrm{p}$ deletion, excepting the oromandibular region. Facial appearance has changed over time, becoming elongated (Figure 2), as described also by Tsukahara et al. [8]. Congenital cardiac defects, present in our case, have been observed in $10.0 \%$ of cases of $18 p$ - [9]. Although the phenotype described above is not characteristic for monosomy $18 \mathrm{p}$, the standing position with widespread legs and leaning slightly forward as well as marked slowness in motion and action are very suggestive for this chromosomal syndrome.

Recurrent 16p11.2 microduplications were initially associated with phenotypes ranging from nor-
Table 1. Comparison of clinical findings in the present case and literature data (modified fromTurleau [2]).

\begin{tabular}{|l|c|c|}
\hline Clinical Features & $\begin{array}{c}\mathbf{1 8 p} \\
\text { Deletion }\end{array}$ & $\begin{array}{c}\text { Our } \\
\text { Patient }\end{array}$ \\
\hline ID (variable severity) & {$[+]$} & {$[+]$} \\
\hline Speech delay & {$[+]$} & {$[+]$} \\
\hline Behavioral disorders & {$[+]$} & {$[+]$} \\
\hline Muscular hypotonia & {$[+]$} & {$[+]$} \\
\hline Short stature & {$[+]$} & {$[+]$} \\
\hline Microcephaly (mild) & {$[+]$} & {$[+]$} \\
\hline Variable features of the HPE spectrum & {$[+]$} & {$[+]$} \\
\hline Round, flat face & {$[+]$} & {$[-]$} \\
\hline Triangular face & {$[-]$} & {$[+]$} \\
\hline Ptosis/epicanthal folds/strabismus & {$[+]$} & {$[-]$} \\
\hline Blue sclera & {$[-]$} & {$[+]$} \\
\hline Flat nasal bridge & {$[+]$} & {$[-]$} \\
\hline Short protruding philtrum/upper lip & {$[+]$} & {$[+]$} \\
\hline Blunted Cupid's bow & {$[+]$} & {$[+]$} \\
\hline Wide mouth & {$[+]$} & {$[-]$} \\
\hline Irregularly set teeth, excessive caries & {$[+]$} & {$[-]$} \\
\hline Microretrognathia & {$[+]$} & {$[+]$} \\
\hline Large protruding ears & {$[+]$} & {$[-]$} \\
\hline Preauricular sinus & {$[-]$} & {$[+]$} \\
\hline Short, webbed neck & {$[+]$} & {$\left[-{ }^{+}\right]$} \\
\hline Broad trunk & {$[+]$} & {$[+]$} \\
\hline Pectus excavatum & {$[+]$} & {$[+]$} \\
\hline Asymmetric mammary glands & {$[-]$} & {$[+]$} \\
\hline Kyphoscoliosis & {$[+]$} & {$[+]$} \\
\hline Wide short hands & {$[+]$} & {$[+]$} \\
\hline Wide short feet & {$[-]$} & {$[+]$} \\
\hline Brachydactyly & {$[-]$} & {$[+]$} \\
\hline Cardiac malformations & {$[+]$} & {$[+]$} \\
\hline Autoimmune diseases & {$[+]$} & {$[-]$} \\
\hline Alopecia & {$[+]$} & {$[-]$} \\
\hline Mild hirsutism & {$[-]$} & {$[+]$} \\
\hline Dystonia & {$[+]$} & {$[-]$} \\
\hline Enuresis & {$[-]$} & {$[+]$} \\
\hline
\end{tabular}

mal to ID, autistic spectrum disorders and psychiatric problems [10-13]. Other studies showed that these duplications can manifest with dysmorphic features without a recognizable pattern, microcephaly, congenital anomalies (including torticollis, cleft lip and palate, pectus excavatum, pectus carinatum, mild scoliosis, hypospadias, phimosis, tethered cord, pes planus), and seizures [14]. Jacquemont et al. [15] showed 
that $16 \mathrm{p} 11.2$ duplication is associated with a BMI $<18.5 \mathrm{~kg}$ per $\mathrm{m}^{2}$ in adults and $<-2$ SD from the mean in children. Among the features mentioned above, our patient exhibited mild microcephaly, pectus excavatum, mild scoliosis and ID, but these features are also described in $18 \mathrm{p}$ deletion. She was underweight during childhood, but recovered later, her BMI being within normal range as an adult. Considering that empiric estimate for penetrance of proximal $16 \mathrm{p} 11.2$ duplication established a penetrance of $27.2 \%$, and the likelihood of a normal phenotype is $\sim 73.0 \%$ [16], we cannot clearly conclude how this copy number variation $(\mathrm{CNV})$ influences the phenotype. More recently, a patient with thoracolumbar syringomyelia and a 16p11.2 duplication has been described [17]. Although our patient presented kyphoscoliosis and nocturnal enuresis, MRI of the spine showed no changes.

In a study of three patients with $18 \mathrm{p}$ deletion, Portnoi et al. [18] suggested that there might be a critical region for GH deficiency between $18 \mathrm{p} 11.23$ and 18pter. Our patient has a deletion which includes that region, but the level of $\mathrm{GH}$ is normal and the craniocerebral $\mathrm{CT}$ did not show any pituitary gland anomalies. The critical region for ID has been tentatively mapped between 18p11.1 and 18p11.21 [4]. Our patient has a deletion distal to this point and moderate ID, but this feature may be due to the $16 \mathrm{p} 11.2$ microduplication. Brenk et al. [19] proposed round face to map to the distal $1.6 \mathrm{Mb}$ of $18 \mathrm{p}$, and post-natal growth retardation and seizures to the distal $8 \mathrm{Mb}$. Our patient has a terminal deletion larger than 10 $\mathrm{Mb}$, but she had no history of seizures, and the face was triangular in childhood and elongated in adulthood. Considering that a pointed chin can be noticed in five out of 13 patients with 16p11.2 duplication for which the facial features were presented $[10,14]$, we appreciate that the triangular aspect of the face may be due to this rearrangement. Ptosis and short neck, frequently associated with 18p- [2], were attributed by Brenk et al. [19] to the proximal half of $18 \mathrm{p}$. These features were absent in our patient, in whom the proximal $5.1 \mathrm{Mb}$ of $18 \mathrm{p}$ was not deleted. Thus, haploin-sufficiency of genes located in this region may be responsible for these features.

Our patient has a microform of HPE, although only $10.0 \%$ of patients carrying an $18 \mathrm{p}$ deletion (including the TGIF gene) present HPE [3]. Holoprosencephaly is a complex developmental disorder in which multiple genetic and environmental factors can affect the severity of the phenotype [20]. A recent array CGH study of a large group of HPE patients demonstrated a high frequency of submicroscopic anomalies involving known but also novel HPE loci, including 16p11.2 [21]. Therefore, the 16p11.2 micro duplication present in our patient can be a second genetic event contributing to HPE manifestation.

In conclusion, we report a female patient with a pseudodicentric $14 ; 18$ chromosome that carries two additional CNVs. These CNVs confer phenotypic variability to $18 \mathrm{p}$ - syndrome, leading to difficulties in establishing the contribution of each abnormality to the phenotype. Although the phenotype of $18 \mathrm{p}-$ syndrome is not as typical as for other syndromes, HPE microform and Turner stigmata associated with characteristic posture and marked slowness in motion and action is very suggestive for this syndrome. Microarray analysis of our patient allowed us to define precise molecular characterization of the translocation breakpoints and to uncover two unsuspected cryptic abnormalities, improving genotype-phenotype correlations and management.

\section{ACKNOWLEDGMENTS}

We thank Pieter van der Vlies, B.Sc. (University Medical Center Groningen, Groningen, The Netherlands) for his support. We also thank the patient and her parents for giving their consent to publish clinical data and photographs.

Declaration of Interest: The authors report no conflicts of interest. The authors alone are responsible for the content and writing of this article.

\section{REFERENCES}

1. de Grouchy J, Lamy M, Theffry S, Arthuis M, Salmon C. Dysmorphic complexe avec oligophrenie: deletion des bras courts d'un chromosome 18. CR Acad Sci. 1963; 256: 1028-1029.

2. Turleau C. Monosomy 18p. Orphanet J Rare Dis. 2008; 3: 4.

3. Schinzel A. Catalogue of Unbalanced Chromosome Aberrations in Humans, 2nd ed. Berlin: Walter de Gruyter; 2001.

4. Wester U, Bondeson ML, Edeby C, Anneren G. Clinical and molecular characterization of indi- 
viduals with $18 \mathrm{p}$ deletion: a genotype-phenotype correlation. Am J Med Genet A. 2006; 140(11): 1164-1171.

5. Sumner AT. A simple technique for demonstrating centromeric heterochromatin. Exp Cell Res. 1972; 75(1): 304-306.

6. Lemyre E, der Kaloustian VM, Duncan AM. Stable non-Robertsonian dicentric chromosomes: four new cases and a review. J Med Genet. 2001; 38(1): 76-79.

7. Marical H, Le Bris MJ, Douet-Guilbert N, Parent P, Descourt JP, Morel F, et al. 18p Trisomy: a case of direct $18 \mathrm{p}$ duplication characterized by molecular cytogenetic analysis. Am J Med Genet A. $2007 ; 143 \mathrm{~A}(18)$ : 2192-2195.

8. Tsukahara M, Imaizumi K, Fujita K, Tateishi H, Uchida M. Familial Del(18p) syndrome. Am J Med Genet. 2001; 99(1): 67-69.

9. Digilio MC, Marino B, Giannotti A, Di Donato R, Dallapiccola B. Heterotaxy with left atrial isomerism in a patient with deletion $18 \mathrm{p}$. Am J Med Genet. 2000; 94(3): 198-200.

10. Fernandez BA, Roberts W, Chung B, Weksberg R, Meyn S, Szatmari P, et al. Phenotypic spectrum associated with de novo and inherited deletions and duplications at $16 \mathrm{p} 11.2$ in individuals ascertained for diagnosis of autism spectrum disorder. J Med Genet. 2010; 47(3): 195-203.

11. Weiss LA, Shen Y, Korn JM, Arking DE, Miller DT, Fossdal R, et al.; Autism Consortium. Association between microdeletion and microduplication at 16p11.2 and autism. N Engl J Med. 2008; 358(7): 667-675.

12. Kumar RA, Marshall CR, Badner JA, Babatz TD, Mukamel Z, Aldinger KA, et al. Association and mutation analyses of $16 \mathrm{p} 11.2$ autism candidate genes. PLoS One. 2009; 4(2): e4582.

13. McCarthy SE, Makarov V, Kirov G, Addington AM, McClellan J, Yoon S, et al. Microduplications of $16 \mathrm{p} 11.2$ are associated with schizophrenia. Nat Genet. 2009; 41(11): 1223-1227.
14. Shinawi M, Liu P, Kang SH, Shen J, Belmont JW, Scott DA, et al. Recurrent reciprocal 16p11.2 rearrangements associated with global developmental delay, behavioural problems, dysmorphism, epilepsy, and abnormal head size. J Med Genet. 2010; 47(5): 332-341.

15. Jacquemont S, Reymond A, Zufferey F, Harewood L, Walters RG, Kutalik Z, et al. Mirror extreme BMI phenotypes associated with gene dosage at the chromosome 16p11.2 locus. Nature. 2011; 478(7367): 97-102.

16. Rosenfeld JA, Coe BP, Eichler EE, Cuckle H, Shaffer LG. Estimates of penetrance for recurrent pathogenic copy-number variations. Genet Med. 2013; 15(6): 478-481.

17. Schaaf CP, Goin-Kochel RP, Nowell KP, Hunter JV, Aleck KA, Cox S, et al. Expanding the clinical spectrum of the 16p11.2 chromosomal rearrangements: three patients with syringomyelia. Eur J Hum Genet. 2011; 19(2): 152-156.

18. Portnoi MF, Gruchy N, Marlin S, Finkel L, Denoyelle F, Dubourg C, et al. Midline defects in deletion 18p syndrome: clinical and molecular characterization of three patients. Clin Dysmorphol. 2007; 16(4): 247-252.

19. Brenk CH, Prott EC, Trost D, Hoischen A, Walldorf C, Radlwimmer B, et al. Towards mapping phenotypical traits in 18p-syndrome by arraybased comparative genomic hybridisation and fluorescent in situ hybridisation. Eur J Hum Genet. 2007; 15(1): 35-44.

20. Ming JE, Muenke M. Multiple hits during early embryonic development: digenic diseases and holopros-encephaly. Am J Hum Genet. 2002; 71(5): 1017-1032.

21. Bendavid C, Rochard L, Dubourg C, Seguin J, Gicquel I, Pasquier L, et al. Array-CGH analysis indicates a high prevalence of genomic rearrangements in holopros-encephaly: an updated map of candidate loci. Hum Mutat. 2009; 30(8): 1175-1182. 